\title{
Impact of smoke-free workplace legislation on exposures and health: possibilities for prevention
}

\author{
M.S. Jaakkola*\#" and J.J.K. Jaakkola*
}

ABSTRACT: The aims of this study were to review experiences with national or statewide smokefree workplace legislation and data on the occurrence of environmental tobacco smoke (ETS) exposure at work, to present the best estimates for health effects related to workplace ETS exposure, and to calculate corresponding population attributable fractions (PAFs) for respiratory and cardiovascular diseases for 14 European countries and the USA.

Systematic searches of the Medline database were carried out, with a cut-off date of November 2005. PAFs for the main outcomes were calculated from the best disease-specific effect estimates and country-specific prevalences of work ETS exposure.

Significant numbers of workers are exposed to ETS at work, i.e. $\sim 7.5$ million workers in 15 European Union countries and 24.6 million in the USA. Workplace ETS exposure is causally linked to lung cancer and coronary heart disease, and is related to an increased risk of asthma in adults and reduced birthweight in newborns. Relatively strong evidence links ETS exposure to chronic obstructive pulmonary disease and stroke. PAFs in Europe and the USA showed that, at current workplace ETS exposure prevalences, the public health impact is substantial.

Experience of national and statewide smoke-free workplace legislation from different countries shows that such legislation leads to significant reductions in employees' environmental tobacco smoke exposure at work, as well as improvements in respiratory and cardiac health.

KEYWORDS: Asthma, chronic obstructive pulmonary disease, coronary heart disease, legislation, lung cancer, tobacco smoke pollution

W hen nonsmokers are situated in the same indoor space as smokers, they inhale tobacco combustion products that are released into the air, i.e. they undergo passive smoking [1]. The smoke inhaled by these nonsmokers is called environmental tobacco smoke (ETS), tobacco-smoke pollution or secondhand smoke, and it is formed mainly of sidestream smoke (SS) and, to a small extent, exhaled mainstream smoke (MS). SS is smoke released into the air from the smouldering end of a cigarette between puffs, whereas MS is smoke inhaled by a smoker during a puff. Both types of smoke contain thousands of chemicals, including $\sim 50$ carcinogenic and tens of irritative and toxic substances [2]. The concentrations of many harmful substances are higher in undiluted SS than in MS [3], but the final concentrations of hazardous compounds inhaled by nonsmokers are determined by factors such as the number of smokers, the number of cigarettes smoked and the volume of the space. It is possible that ETS also adds to the risk that smoking poses to the smokers themselves, but this has not been studied in detail.

Since the 1970s when studies first linked passive smoking to an increased risk of lower respiratory infections in children, and the 1980s when the first studies in adults linked passive smoking to lung cancer, increasing evidence has accumulated on the adverse health effects related to ETS exposure [3-8]. Adverse effects have been detected in relation to ETS exposure in different micro-environments, including the home, workplaces, social situations and even in vehicles. The important question today is the following: how to prevent these ill-health effects in an effective way in both child and adult populations? For children, the main exposure source is smoking in
AFFILIATIONS

*Institute of Occupational and Environmental Medicine, University of Birmingham, Birmingham, UK. \#Dept of Respiratory Medicine, University of Oulu, Oulu, Finland.

CORRESPONDENCE

M.S. Jaakkola

Institute of Occupational and Environmental Medicine University of Birmingham Edgbaston Birmingham B15 2TT UK Fax: 441214146217 E-mail: M.Jaakkola@bham.ac.uk

Received:

January 042006

Accepted after revision:

February 192006

SUPPORT STATEMENT

This work was supported by the West Midlands Levy Board (Birmingham, UK). 
homes, and measures that could be taken to prevent children's exposure have been discussed previously [4, 6]. When considering adult populations, both the home and workplace are important for exposure, since adults spend the majority of their time in these two environments.

The objectives of this article are to review the experience with national or statewide smoke-free workplace legislation, examine data on the occurrence of ETS exposure at work, present the best estimates for health effects related to workplace ETS exposure, and calculate population attributable fractions (PAFs) due to occupational ETS exposure for several diseases in several European countries and the USA.

\section{METHODS}

Systematic searches of the Medline database were carried out and other sources of recent publications were used from 1966 until November 2005. When presenting the data, the current authors focused on results from meta-analyses and the most recent publications.

The health impact of workplace exposure to ETS in several European countries and the USA was roughly estimated by calculating population attributable fractions using the best available disease-specific effect estimates (odds ratio (OR) or incidence rate ratio) and country-specific prevalences of workplace exposure from the available literature $[9,10]$. The attributable fraction (AF) was calculated as $\mathrm{AF}=(\mathrm{OR}-1) / \mathrm{OR}$ and the $\mathrm{PAF}$ as $\mathrm{PAF}=\mathrm{P} \times \mathrm{AF}$, where $\mathrm{P}$ is the prevalence of exposure.

\section{EXPERIENCE WITH SMOKE-FREE LEGISLATION}

This section reviews the impact of smoke-free workplace legislation on exposure, health effects and/or attitudes in three countries: Finland, as an example from Northern Europe; Ireland, as another example from Europe; and the states of California and Montana as examples from the USA. The experience is presented in chronological order, and the main findings are summarised in table 1.

\section{The Finnish experience}

In Finland, the first national Tobacco Act, which included measures for tobacco control, came into effect in 1977. This Act was revised in the early 1990s and the new law came into effect in March 1995 comprising measures aimed at preventing employees from being exposed to ETS in the workplace. The 1995 law implemented smoking restrictions in all public premises and all premises shared by employees. The responsibility to protect employees from passive smoking was allocated to employers, who were given the two following options: 1) to impose a total ban on smoking; or 2) to provide designated smoking spaces with separate ventilation system and a lower air pressure compared with the surrounding spaces to prevent any escape of smoke into the nonsmoking areas. In 2000, the Act was extended to cover restaurants and bars, which were exempted in 1995. In addition, the 2000 law recognised ETS as a known human carcinogen.

The impact of the 1995 law on exposure of employees was studied in nine large- or medium-sized workplaces in South Finland 1 yr [11] and 3 yrs [12] after the implementation of the new law and compared with the situation before the revised Act. Eight workplaces participated in the 4-yr follow-up. The workplaces were selected from the Helsinki metropolitan area and represented private and public sectors, including three different branches of workplace: industry, service sector and offices. The workplaces had varying degrees of voluntary smoking restrictions (but no total ban) at the baseline. Exposure assessment was based on questionnaire reports and measurements of air nicotine in the participating workplaces [11-13]. The air nicotine samples were collected in cafeterias and shared workrooms and, after the 1995 law, especially from corridors or workrooms near designated smoking areas. Attitudes were also assessed with the questionnaire. The number of respondents was 880 in 1994-1995, 940 in 19951996, and 659 in 1998 (response rate 70-75\%).

A significant decline in ETS exposure was observed from baseline to 1998 [12] (table 1). One-third of the nonsmoking employees reported highest work exposure ( $>4 \mathrm{~h}$ daily) at baseline, whereas only 3\% reported such exposure 3 yrs after the revised Act had come into effect. Only one-fifth reported no daily work ETS exposure at baseline, whereas $71 \%$ of employees reported no exposure 3 yrs after the law. The most dramatic decline in exposure was seen among industrial workers, but a similar trend was also detected in office and service workers. However, in the service sector, the largest decline of exposure was seen after $1 \mathrm{yr}$ and somewhat less favourable development was observed between 1 and 3 yrs, suggesting that more attention should be paid to enforcement of the law in the long term. The median indoor-air nicotine concentration fell significantly in all types of workplaces after the new law and remained low in the 1998 study (industry: from 1.2 to $0.05 \mu \mathrm{g} \cdot \mathrm{m}^{-3}$; service sector: from 1.5 to $0.17 \mu \mathrm{g} \cdot \mathrm{m}^{-3}$; offices: from 0.4 to $0.05 \mu \mathrm{g} \cdot \mathrm{m}^{-3}$ ), confirming the questionnairebased results.

Personal smoking prevalence decreased significantly between the baseline and 1-yr follow-up (males: 33.1 to $26.9 \%$; females: 22.0 to $18.4 \%$ ). In 1998, smoking decreased further among males $(24.8 \%)$, but rose among females $(26.1 \%)$. The overall number of smoking females was small in this sample, so the findings in females may be explained by random variation. The average number of cigarettes smoked daily by smokers declined from 19 at baseline to 16 in the follow-up studies. Employees' attitudes concerning preferred workplace smoking policy showed a trend from 1994-1995 to 1998 with more restrictive workplace policies becoming increasingly favoured by both nonsmokers and smokers (table 1). In 1998, only $4 \%$ of nonsmokers and $11 \%$ of smokers favoured no restrictions.

\section{The Californian experience}

In California, Proposition 99, which included an extensive tobacco-control programme, was enacted in 1988. Among other measures, this programme emphasised the importance of clean indoor air. Statewide California smoke-free workplace law came into effect in January 1995 and was extended to bars and taverns in January 1998 to prohibit smoking on all such premises.

Starting in 1998, an annual cross-sectional survey was carried out in Los Angeles County, including a sample representing 8$10 \%$ of the 9,000 bars and restaurants with an alcohol licence in that area [14] (table 1). Based on site observations, the compliance to the law by patrons increased in bars from 46 


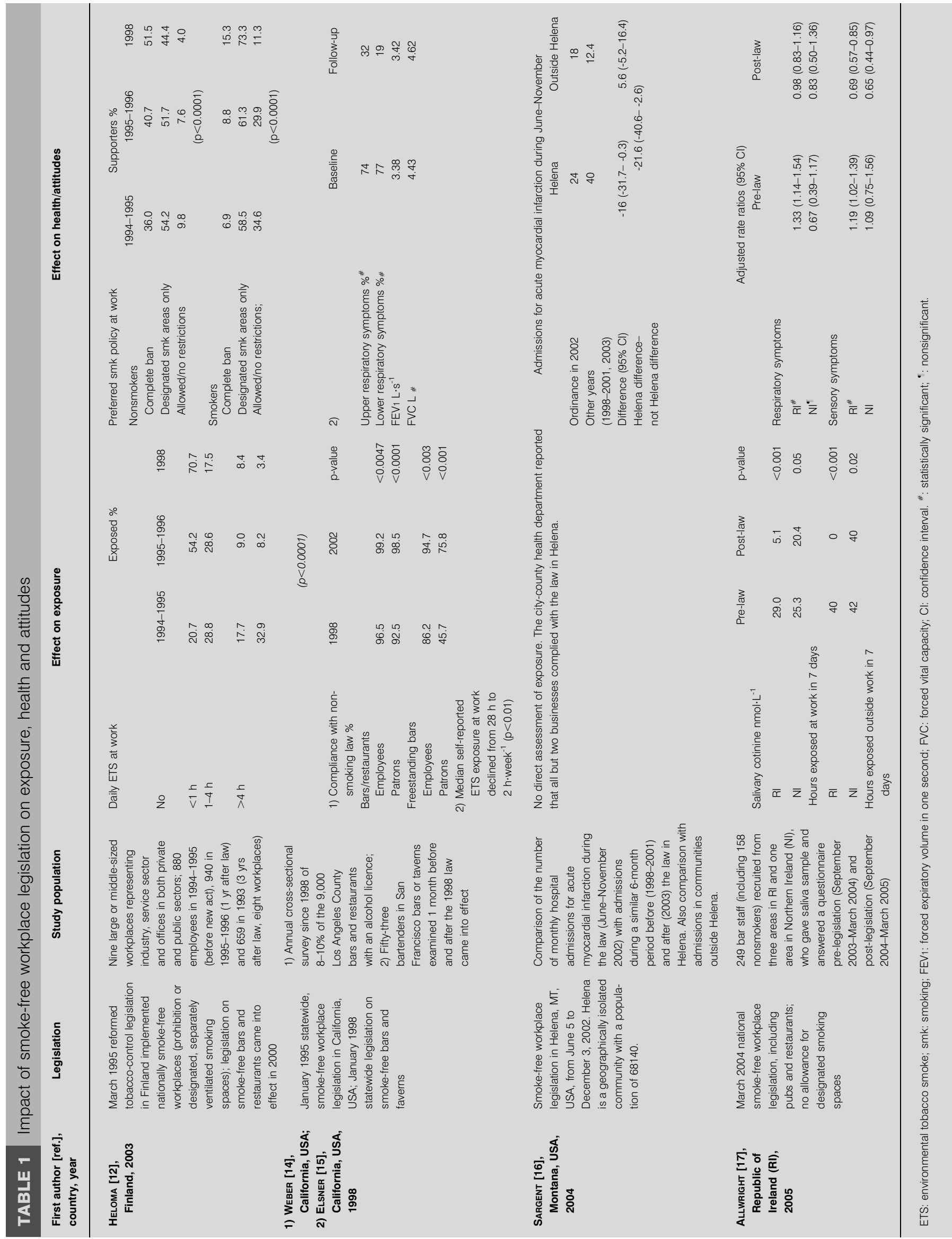


to $76 \%$ and in restaurants from 92 to $99 \%$ between 1998 and 2002. Employee compliance increased from 86 to $95 \%$ in bars and from 97 to $99 \%$ in restaurants. Another study from San Francisco of 53 bartenders inquired about their ETS exposure and respiratory symptoms $\sim 1$ month before and 1 month after the 1998 law had come into effect [15]. The study participants also performed spirometry. Self-reported median workplace exposure declined from 28 to $2 \mathrm{~h} \cdot$ week $^{-1}$ (table 1 ). This was accompanied by a significant decline in upper respiratory irritative symptoms (eye, nose and throat symptoms) from 77 to $19 \%$, as well as in lower respiratory symptoms (wheezing, dyspnoea, cough and phlegm production) from 74 to $32 \%$. Both average forced expiratory volume in one second (FEV1) and forced vital capacity increased at follow-up. The sample included both nonsmokers and smokers, but adjusted for personal smoking in the analyses.

\section{The Montana experience}

The experience from Montana is an example of a smaller community, and involves a geographically isolated community in Helena (table 1). A law prohibiting smoking in workplaces and public places came into effect there in June 2002, but was suspended in December 2002 due to opposition against the law. Monthly hospital admissions for acute myocardial infarction were calculated for a 6-month period from June to November before (1998-2001), during (2002) and after (2003) this ordinance was in effect in Helena, and the results were compared with areas outside Helena [16]. The diagnosis of acute myocardial infarction was based on primary or secondary diagnosis at discharge or in the emergency room. The number of admissions in the 6-month period in 2002 (when the law was in effect) was compared with the other 6-month periods. When the smoke-free legislation was in force, there was a significant reduction in admissions by $-16 \quad(95 \%$ confidence interval (CI) -31.7- -0.3) compared with the other years in Helena. In contrast, in the area outside Helena (which had no smoke-free law), there was a nonsignificant increase in the number of admissions in 2002 compared with the other years.

\section{The Irish experience}

In the Republic of Ireland, a national smoke-free legislation covering all indoor workplaces came into effect in March 2004. This law does not permit any designated smoking rooms. A study on pub workers recruited 249 participants from three areas in the Republic of Ireland and one area in Northern Ireland in the 6-month period preceding the ban, and carried out a follow-up 1 yr later (i.e. 6-12 months after the law had come into effect) [17]. Northern Ireland served as a comparison area with no smoke-free law. A total of 158 (63\%) pub workers were nonsmokers and participated in the follow-up. They answered a questionnaire on ETS exposure and respiratory symptoms and gave a saliva sample for cotinine analysis. Selfreported exposure to ETS declined significantly from a median of $40 \mathrm{~h} \cdot$ week $^{-1}$ to 0 after the ban in the Republic, whereas no such decline was observed in Northern Ireland (table 1). Exposure outside the home also declined significantly in the Republic (from a median of $4 \mathrm{~h} \cdot$ week $^{-1}$ to 0 ), whereas exposure somewhat increased in Northern Ireland. Salivary cotinine concentration also demonstrated a decline of $71 \%$ (from 35.8 to $10.2 \mathrm{nmol} \cdot \mathrm{L}^{-1}$ ) in the Republic compared with $34 \%$ (from 35.2 to $23.3 \mathrm{nmol} \cdot \mathrm{L}^{-1}$ ) in Northern Ireland. The small decline observed in Northern Ireland was attributed to a recent decline in the pub trade. The decline in exposure in the Republic of Ireland was paralleled by a decrease in respiratory symptoms, with significant reductions being seen in cough and phlegm production. In addition, sensory symptoms declined after the ban, with significant reductions being observed in the occurrence of red eyes and sore throat. In Northern Ireland, the occurrence of lower respiratory symptoms was constant, but sensory symptoms declined somewhat.

\section{EXPOSURE AT WORK}

For the purpose of estimating exposure to ETS in the workplace among different populations, population-based studies provide the best information. Such studies from Africa, Asia, Australia, New Zealand, Europe and the USA were recently reviewed by the International Agency for Research on Cancer (IARC) [8]. Questionnaire-based assessment and air measurements of tobacco-smoke constituents are the most suitable assessment methods for estimating exposure in different microenvironments [1, 2]. Table 2 summarises the data on ETS exposure at work in Europe, the USA and some other countries.

The most recent estimates of exposure to ETS at work in European countries are reported by the Europe-wide database CAREX on occupational exposure to carcinogens [18] and by the population-based cross-sectional European Community Respiratory Health Survey (ECRHS) [19] (table 2). The CAREX database includes data on workers' exposure to agents classified as carcinogenic to humans (IARC class 1) or probably carcinogenic to humans (IARC class $2 \mathrm{~A}$ ), ionising radiation, and some selected agents that are possibly carcinogenic to humans (IARC class 2B). It currently comprises information from 15 European Union countries, and data on new countries can be added to the database and existing estimates can be updated. According to a CAREX-based report in 2000 [18], ETS exposure (classified as a class 1 carcinogen by the IARC) was the second most common carcinogen exposure in European workers. A total of 7.5 million workers are exposed to ETS for $\geqslant 75 \%$ of their working time. ETS is the most common occupational carcinogenic exposure in Great Britain, the Netherlands and Italy.

The ECRHS [19] provided estimates of both home and work ETS exposure for several European countries and also some countries outside Europe. Exposure at work was defined as an affirmative answer to the question: "Do people smoke regularly in the room where you work?" The highest proportions of populations exposed to ETS at work were found in Spain (32-54\%), Italy (30-42\%) and the Netherlands $(29-38 \%)$, whereas the lowest were detected in Sweden (3$10 \%)$, New Zealand (5-10\%), Portland (OR, USA; 7\%) and Australia (8\%). In almost all countries, ETS exposure was more common at work than at home, although countries with the lowest workplace exposure were exceptions to this. A population-based 15-yr follow-up study from Finland [20] showed that ETS exposure at work for $\geqslant 1 \mathrm{~h} \cdot \mathrm{day}^{-1}$ among nonsmoking employed adults declined in males from $23 \%$ in 1985 to $8 \%$ in 2000 and in females from 16 to $4 \%$ (table 2). This declining trend reflects, at least in part, the influence of the 1995 national smoke-free workplace legislation. 
TABLE 2 Occurrence of environmental tobacco smoke (ETS) exposure at work

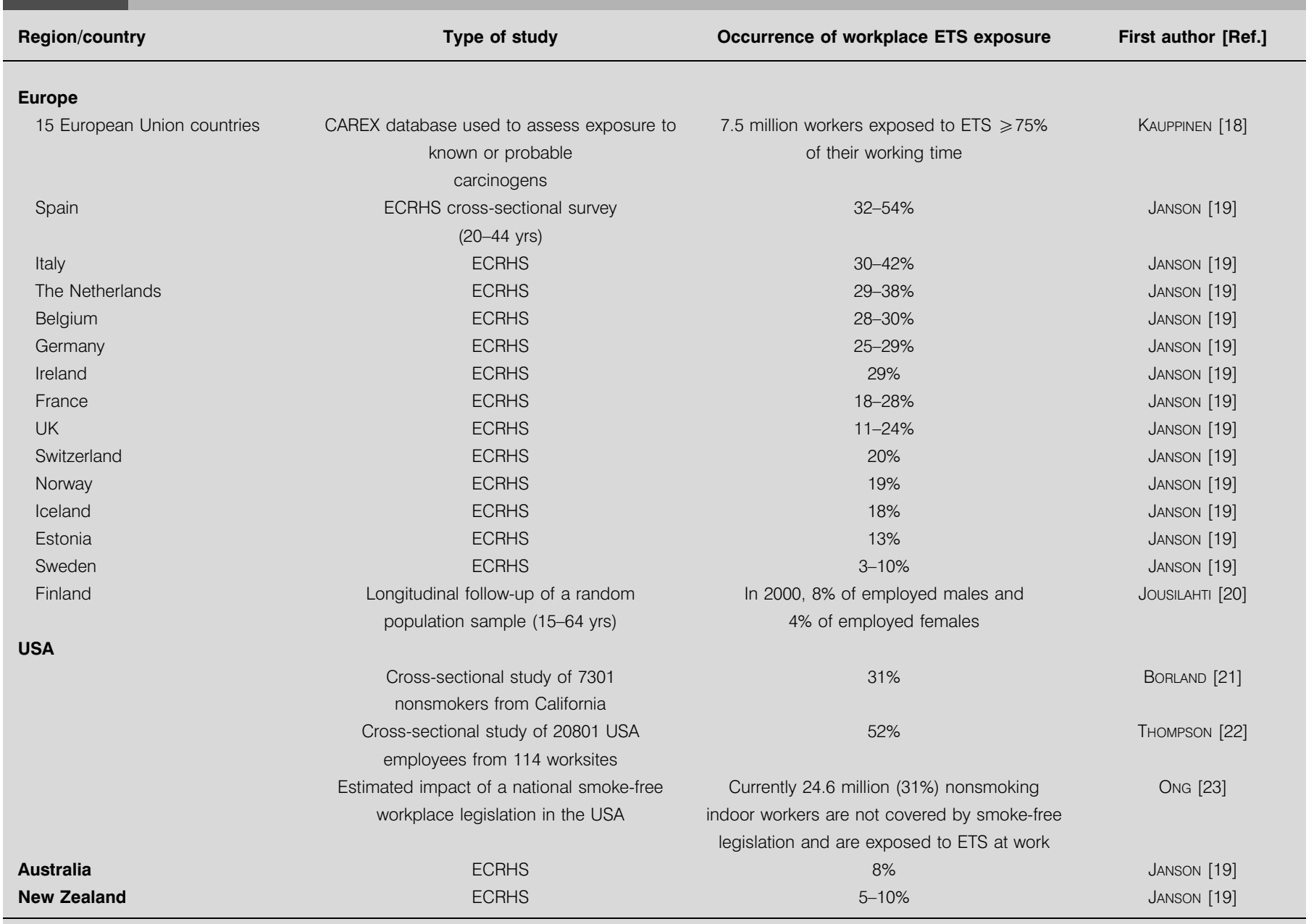

ECRHS: European Community Respiratory Health Survey.

In a cross-sectional study of 7,301 nonsmokers from California, which was conducted in the early 1990s, 31\% of workers reported ETS exposure at work [21]. Exposure was more common among males (36\%) than females $(23 \%)$, and in those with less education ( $43 \%$ for those with $<12$ yrs of education) compared with those with longer education (19\% for those with $\geqslant 16$ yrs of education). In a cross-sectional study, where THOMPSON et al. [22] examined $\sim 20,800$ USA employees from 114 worksites, a total of $52 \%$ of the participants were exposed to ETS at work. ONG and GLANTZ [23] estimated that 24.6 million indoor workers in the USA are exposed to ETS at work, while taking into account that $69 \%$ of indoor workers are already covered by smoke-free workplace legislation and, among those not covered, $\sim 8.6$ million are active smokers.

Studies that have measured air concentrations of ETS markers (mainly nicotine and/or respirable suspended particulates) have demonstrated in general that average levels of ETS exposure are comparable in home and work environments that do not have smoking restrictions, but that some work environments, such as bars and restaurants, have exceptionally high exposure levels [2, 3, 24-27].

\section{HEALTH-EFFECT ESTIMATES}

This section provides an update on the effects of ETS exposure on respiratory and cardiovascular diseases in adults, with special focus on workplace exposure. The effect estimates chosen by the authors as best estimates, based on justifications given in the text, are presented in table 3.

\section{Lung cancer}

Since the first publications on passive smoking and lung cancer in 1981, a substantial number of studies have addressed this relationship in different parts of the world, including eight cohort studies and $\sim 50$ case-control studies $[4,8,28]$. These were reviewed recently by IARC [8] and BOFFETTA [28]. A total of 23 studies assessed the risk of lung cancer in relation to ETS exposure at work. Several of these studies found evidence of a dose-response relationship between increasing workplace exposure, in terms of duration or intensity, and increasing risk of lung cancer, and such a relationship was found particularly in studies with a strong study design [35-39]. Several meta-analyses have been performed separately for lung cancer in relation to different sources of exposure, including spouse, workplace and childhood exposure. The 
TABLE 3 Summary of health-effect estimates for workplace exposure to environmental tobacco smoke

\begin{tabular}{lccc} 
Disease & OR (95\% $\mathbf{~ I ) ~}$ & $\begin{array}{c}\text { Number of studies the estimate is based on } \\
\text { (meta-analyses) or selected from }\end{array}$ & First author [Ref.] \\
\hline Lung cancer & $1.17(1.04-1.32)$ & 16 (meta-analysis) & BOFFETTA [28] \\
Coronary heart disease & $1.21(1.04-1.41)$ & 5 (meta-analysis) & STEENLAND [29] \\
Asthma & $2.16(1.26-3.72)$ & 9 & 9 \\
COPD & $1.36(1.002-1.84)$ & 17 & JAAKKOLA [30] \\
Low birthweight & $1.43(0.50-4.12)$ & 6 & EISNER [31] \\
Stroke & $1.82(1.34-2.49)$ & 1 & JAAKKOLA [32] \\
Severe pneumonia & $2.5(1.2-5.1)$ & & BONITA [33] \\
\hline
\end{tabular}

OR: odds ratio; $\mathrm{Cl}$ : confidence interval; COPD: chronic obstructive pulmonary disease.

summary estimates of OR $(95 \% \mathrm{CI})$ in relation to workplace ETS exposure from the most recent meta-analyses are: 1.39 (1.15-1.68) for males and females combined by WeLLS et al. [40] based on five studies; 1.16 (1.05-1.28) for males and females combined by ZHONG et al. [41] based on 14 studies; 1.17 (1.041.32) for males and females combined by BofFETTA [28] based on 16 studies; and 1.19 for females (1.09-1.30), 1.12 for males $(0.80-1.56)$ and $1.03(0.86-1.23)$ for females and males combined by IARC based on 19, six and seven studies, respectively [8]. The current authors selected the estimate of 1.17 [28] as the best estimate (table 3), since it was based on the largest number of studies looking at females and males.

\section{Coronary heart disease}

Coronary heart disease (CHD) is another adult disease that has been studied extensively in relation to ETS exposure. These studies have been recently reviewed and meta-analyses performed based on them [29, 42-46]. To date, $\sim 20$ studies have been published on ETS exposure and CHD, including 10 cohort studies and $>10$ case-control studies. Less than half have assessed the risk related to workplace exposure separately. The outcome has been either fatal or nonfatal myocardial infarction. Several studies have indicated a dose-response relationship between the intensity of ETS exposure and the size of the relative risk. The estimated summary ORs (95\% CI) from the most recent meta-analyses are: $1.22(1.14-1.30)$ for fatal and 1.32 (1.04-1.67) for nonfatal cardiac events in relation to home exposure (based on 17 studies) by THUN et al. [44]; 1.25 (1.171.32) for home and/or work exposure (based on 17 studies) by HE et al. [45]; and 1.21 (1.04-1.41) for workplace exposure (based on five studies) by STEENLAND [29]. In addition, a recent meta-analysis by KAUR et al. [47] focused on ETS exposure and risk of fatal heart disease in females, giving a summary relative risk of 1.15 (1.03-1.28) based on nine cohort studies. A recent cohort study from the UK with 20 yrs of follow-up found a somewhat higher risk of CHD among passive smokers when exposure assessment was based on serum cotinine [48]. Comparing the higher quartiles of cotinine concentration to the lowest quartile, the following adjusted hazard ratios (95\% CI) for CHD were detected: second quartile 1.45 (1.01-2.08); third quartile 1.49 (1.03-2.14); and fourth quartile 1.57 (1.082.28). Considering that the focus of the current article is ETS exposure at work, the best effect estimate was chosen as 1.21 (table 3) based on the recent meta-analysis that focused on workplace exposure [29].

In addition to its effect on induction of CHD, ETS exposure has been shown to significantly increase platelet adhesion, blood coagulability and arterial endothelial damage [46, 49, 50]. Cardiac exercise tolerance has decreased in relation to ETS exposure, especially among CHD patients [5, 46, 51]. These effects add to the risk of acute cardiac events.

\section{Asthma}

There is abundant evidence suggesting that ETS exposure plays a causal role in the development of childhood asthma, as reviewed by JAAKKOLA and JAAKKOLA [6], but the relationship between ETS exposure and adult asthma has been studied to a lesser extent. However, recently, there has been increasing interest in this subject and, to date, one longitudinal [52], one incident case-control [30], two prevalent case-control [53, 54] and approximately five cross-sectional studies have been published (as reviewed by JAAKKOLA and JAAKKOLA [7]). Some of the larger cross-sectional studies, such as the ECRHS, have published several reports from their data [19, 55]. All of these studies found an increased risk of asthma in relation to ETS exposure in adulthood, although the risk was not always statistically significant $[53,56]$. The effect estimate, usually ORs, from these studies ranged 1.15-4.7 [7]. Several studies showed evidence of a dose-response relationship between ETS exposure and asthma, when the magnitude of ETS exposure was measured as the number of smoking household members or co-workers, the average number of cigarettes the person was exposed to daily, duration of exposure or a cumulative index [19, 30, 56-58]. Many of the studies found a stronger effect related to workplace exposure than to home exposure $[19,52,53,59]$. The population-based Finnish case-control study with new (incident) cases of adult asthma found a higher OR for home exposure (4.77) than work exposure, but exposure at home was not common among the study population (2-3\%) and, hence, the OR was not very precise (95\% CI 1.29-17.7). In contrast to this, the work exposure OR of 2.16 had a reasonably narrow confidence interval (95\% CI 1.26-3.72), being relatively precise [30]. This study showed evidence of a dose-response relationship between the increasing number of cigarettes the person was exposed to at work in the past year and the risk of asthma. 
Workplace ETS exposure occurred among 9\% of controls and $16 \%$ of asthma cases. The OR for ETS exposure in the workplace from a 10-year follow-up study of Californian Seventh-Day Adventists [52] was 1.45 (95\% CI 1.21-1.80) for incident asthma. Since the diagnosis of asthma was based on careful clinical investigations in the Finnish study, including lung function measurements, such as spirometry, bronchodilation test and 2week peak expiratory flow surveillance, whereas the study from California relied on self-report, the value of 2.16 from the Finnish study [30] was chosen as the best estimate (table 3).

\section{Chronic obstructive pulmonary disease}

Active smoking has been identified as the most important cause of chronic obstructive pulmonary disease (COPD) for a long time [60], but surprisingly few studies have investigated the role of adult ETS exposure in the development of COPD. A review published in 2002 [7] identified six studies, including three longitudinal and three case-control studies, and most of these reported the effect of household smoking on COPD, with the OR ranging 1.5-5.6. Only the 10-yr follow-up study of Californian Seventh-Day Adventists assessed exposure both at home and at work, and gave an OR of 1.48 (95\% CI 0.95-2.23) for combined adulthood exposure [61]. More recently, a population-based cross-sectional study of 2,113 adults aged 55-75 yrs from 48 USA states assessed the association between lifetime ETS exposure at home and at work and COPD, defined as self-reported physician diagnosis of chronic bronchitis, emphysema or COPD [31]. An increased risk of COPD was observed in relation to the highest quartile of home exposure (OR (95\% CI) 1.55 (1.09-2.21)) and the highest quartile of work exposure (OR (95\% CI) 1.36 (1.002-1.84)), after adjustment for smoking history and other confounders. When applying a more specific diagnosis based on emphysema and COPD only, the ORs were 2.38 (1.42-3.90) and 1.79 (1.21-2.65) for home and work exposures, respectively. Two recent cohort studies, a 7-yr follow-up of the European Prospective Investigation into Cancer and Nutrition (EPIC) cohort [62] and a retrospective cohort study from Hong Kong [63], investigated the relationship between ETS exposure and COPD mortality. In the Hong Kong study, the adjusted OR related to spousal smoking was 1.67 (0.95-2.94) in never-smoking males and $2.90(1.34-6.29)$ in never-smoking females [63]. There was a significant doseresponse relationship with the number of smokers living with the study subject (males and females combined). In the EPIC study, the adjusted OR of respiratory mortality (including COPD, emphysema, lung cancer and upper respiratory cancers) was $1.11(0.71-1.74)$ for home exposure and 1.55 (1.03-2.32) for work exposure [62]. No estimate was given for COPD alone, probably due to the small number of study subjects that had died from these diseases. The best effect estimate for ETS and COPD was chosen as 1.36 (table 3) based on the population-based USA study, which separately assessed the risk related to home and work ETS exposures [31].

In addition to the studies on ETS exposure and COPD, there is abundant evidence that indirectly suggests that ETS is a risk factor for COPD. More than 10 studies have shown an increased risk of chronic respiratory symptoms in relation to ETS exposure at home and/or at work with both crosssectional [7] and longitudinal [64, 65] study designs, as reviewed by JAAKKOLA and JAAKKOLA [7]. More recent studies have confirmed the significant risk of chronic bronchitis and other respiratory symptoms in relation to ETS exposure in adulthood [55, 59]. Approximately 24 studies have addressed the relationship between ETS exposure in adulthood and lung function [7]. A meta-analysis in 1999, based on nine crosssectional studies, found a significant, although relatively small, reduction in FEV1 related to ETS exposure, with an effect estimate of $-2.7 \%$ (95\% CI $-4.1--1.2 \%$ ) [66]. Results from later studies have been consistent with this estimate [19, 67]. A crosssectional Canadian study of young adults found that cumulative exposure to ETS at work was significantly related to a decrease in diffusing capacity of the lungs among females [68].

\section{Low birthweight and pre-term delivery}

There are two sources of ETS exposure for a foetus: 1) maternal active smoking; or 2) maternal exposure to ETS during pregnancy [6]. There is abundant evidence on the adverse effects of maternal active smoking on the health and development of the foetus $[6,69,70]$, but the focus of the current article is on maternal passive smoking, since this is the exposure that can best be influenced by smoke-free workplace legislation. Maternal passive smoking has been linked in several studies to both low birthweight (LBW) and pre-term delivery, the evidence being stronger for LBW [70]. Two recent metaanalyses on ETS exposure during pregnancy and mean birthweight have assessed the difference in birthweight between exposed and unexposed newborns as -31 (-44- -19) $\mathrm{g}$ (based on 11 studies) [71] or $-29(-41--16) \mathrm{g}$ (based on 11 studies of nonsmoking mothers) [72]. The effect of maternal passive smoking on the risk of LBW, defined as weight $<2,500$ g (at term) or small for gestational age (SGA), has also been addressed in several studies. The meta-analysis by WINDHAM et al. [72] estimated the summary OR as 1.19 (1.08-1.32), and most of the more recent studies have shown an increased risk of LBW or SGA in relation to ETS exposure, at least in the highest exposure categories [32, 73-76]. The Finnish population-based study of 389 newborns assessed maternal ETS exposure at home and work separately and validated combined exposure by measurements of hair nicotine concentration, which assessed exposure in the last 2 months before birth (i.e. third trimester) [32]. A dose-response relationship was found with increasing hair nicotine concentration for both LBW and preterm delivery; the adjusted OR of LBW was 1.28 (95\% CI 0.59$2.60)$ for $0.75-<4.00 \mu \mathrm{g} \cdot \mathrm{g}^{-1}$ of nicotine and $1.55(0.55-4.43)$ for $\geqslant 4.00 \mu \mathrm{g} \cdot \mathrm{g}^{-1}$, the corresponding ORs for pre-term delivery were $1.30(0.30-5.58)$ and $6.12(1.31-28.7)$, respectively. The adjusted OR of LBW related to work ETS only was 1.43 (0.50$4.12)$ and to home and work exposure combined $2.08(0.44-$ 9.73), with the corresponding ORs of pre-term delivery being $2.35(0.50-11.1)$ and $8.89(1.05-75.3)$, respectively. The best estimate was selected as OR $1.43(0.50-4.12$; table 3) [32], as the Finnish study assessed the effect of workplace exposure in particular. This estimate had a relatively large confidence interval as a result of a small sample size, but it is consistent with the estimates from other studies, and it is based on a good exposure assessment method and adjusted for a wide range of potential confounders.

\section{Stroke}

A limited number of studies have addressed the role of ETS exposure for stroke [33, 48, 63,77-79], although active smoking 
has been shown to be a significant risk factor for this disease [46]. In a population-based case-control study from New Zealand [33], the adjusted OR of nonfatal and fatal stroke related to ETS at home and/or at work was 1.82 (95\% CI 1.342.49), and was significant both in males and females. In a 16-yr follow-up study from California, 27,698 never-smokers from a health-maintenance organisation were followed for hospitalisation or death due to stroke [78]. ETS exposure at home for $\geqslant 20 \mathrm{~h} \cdot$ week $^{-1}$ was related to ischaemic stroke in males (OR (95\% CI) $1.29(0.75-2.2 .0))$ and in females (1.5 (1.07-2.09)), whereas no such association was reported for exposure outside the home. In a 20-yr follow-up of 2,105 nonsmoking males from the British regional heart study [48], the risk of fatal and nonfatal stroke increased with increasing serum cotinine concentration among never-smokers, although no increase in risk was detected when ex-smokers were included in the study population. Among never-smokers, the adjusted ORs (95\% CI) for quartiles of cotinine concentration compared with the lowest quartile were as follows: second quartile $1.34(0.53-$ 3.40); third quartile 1.39 (0.48-4.04); and fourth quartile 2.16 (0.80-5.80). All confidence intervals included the value of 1 , which is probably explained by a small number of subjects in each subcategory. A retrospective cohort study from Hong Kong found an increased risk of stroke in relation to spousal smoking in females (OR (95\% CI) 1.57 ( 1.11-2.27)) and males (1.31 (0.87-1.94)), with fewer males being exposed to ETS at home [63]. The risk for females and males combined increased significantly with increasing number of smokers at home. A cross-sectional study of 60,377 nonsmoking Chinese females from Shanghai found an increasing risk of prevalent stroke with increasing number of cigarettes smoked by the spouse, as well as with increasing duration of the spouse's smoking [79]. The adjusted OR for the spouse's current smoking was 1.41 (95\% CI 1.16-1.72). The best estimate was selected as an OR of 1.82 (table 3 ), since the study from New Zealand also assessed exposure at work [33].

\section{Pneumonia}

In children, parental smoking has been shown to be a significant risk factor for lower respiratory infections $[4,6]$, but only one study on this topic was identified among adults. A population-based case-control study of adults from the USA investigated the relationship of active smoking and exposure to ETS with invasive pneumococcal disease, mainly pneumonia, in immunocompetent adults [34]. Among nonsmokers, the adjusted OR (95\% CI) of invasive pneumococcal infections in relation to ETS exposure was 2.5 (1.2-5.1). The risk was of similar magnitude in relation to home exposure as with exposure outside the home. A dose-response relationship was observed between the hours of daily ETS exposure and the risk of pneumococcal disease. The best effect estimate was chosen as 2.5 (table 3 ).

\section{BURDEN OF DISEASE DUE TO OCCUPATIONAL ETS EXPOSURE}

A few studies have made an attempt to estimate the impact of smoke-free workplace legislation on burden of disease. A study from Finland [80] addressed the mortality from respiratory and cardiovascular diseases that was attributable to occupational ETS exposure by calculating PAFs. The study used exposure estimates from the Quality of Working Life
Survey by Statistics Finland (Helsinki), defining exposed as those who reported ETS exposure for $\geqslant 25 \%$ of their working hours. The exposure prevalences were $12 \%$ for males and $8 \%$ for females, or $10 \%$ for the total population. Risk estimates for diseases were chosen by reviewing the epidemiological literature. Cause-, sex- and age-specific mortality statistics for 1996 were obtained from Statistics Finland, with the cause of death being based on the underlying cause of death as classified using the International Classification of Diseases (10th revision). The age range of interest was 25-69 yrs, and for some diseases with a long latency period, such as lung cancer, older age groups were also included. In 1996, the total Finnish population aged $\geqslant 25$ yrs was 3.5 million. The PAFs and the number of deaths (males and females combined) related to workplace ETS exposure were as follows: lung cancer PAF $2.8 \%, \mathrm{n}=52$; COPD PAF $1.1 \%, \mathrm{n}=11$; asthma PAF $4.5 \%, \mathrm{n}=4$; pneumococcal infections PAF $14.3 \%, \mathrm{n}=1$; ischaemic heart disease PAF 3.4\%, $n=106$; and stroke PAF 9.4\%, $n=78$. The fraction of total mortality due to workplace ETS was $0.9 \%$, corresponding to 252 deaths in 1996. The largest PAFs were found for asthma, pneumonia and stroke, whereas the greatest numbers of death were contributed by heart disease, lung cancer and stroke. The latter diseases are common with relatively high fatality, which explains their significant contribution to numbers of deaths. The study concluded that ETS exposure at work was related to a high burden of disease, which could be prevented by measures reducing exposure at workplaces, including smoke-free workplace legislations.

A report from the USA estimated the reduction of cardiovascular disease assuming that all USA indoor workers would be covered by a smoke-free workplace policy [23]. Currently, $\sim 69 \%$ of indoor workers are protected by such a law, whereas $31 \%$ are not. Reduction in passive smoking was estimated to account for $60 \%$ of the decline in myocardial infarctions, whereas quitting smoking accounted for $40 \%$. Only the impact of quitting smoking was calculated in the case of strokes, so the estimate was conservative. The overall reduction in cardiovascular disease was estimated to be 1,900 in the first year $(1,540$ acute myocardial infarctions and 360 strokes) and the overall reduction in deaths was 610 (480 due to cardiac disease and 130 due to stroke). Over a 7-yr period, it was estimated that 7,520 acute cardiovascular diseases could be prevented $(6,250$ myocardial infarctions and 1,270 strokes). The number of deaths prevented would be 2,420 (1,960 due to myocardial infarction and 460 due to stroke). This model assumed that by introducing a nation-wide legislation, all passive smoking exposure at work would cease and the quitting rate among active smokers would be $14.7 \%[23,81]$. The model did not take into account reduction in passive smoking outside work or cigarettes consumed by active smokers as a consequence of such legislation.

\section{ESTIMATED HEALTH IMPACT OF WORKPLACE ETS}

The health impact of workplace exposure to ETS was roughly estimated based on current or latest available levels of workplace ETS exposure in several European countries and the USA from recent studies summarised in table 2. PAFs were calculated for lung cancer, CHD, asthma, COPD, LBW, stroke and severe pneumonia for 14 European countries and the USA using the effect estimates given in table 3 , selected as the best 
estimates based on previously discussed justifications (Healtheffect estimates section). These estimates were from recent meta-analyses or from individual studies. In brief, in the case of meta-analyses, the most recent estimate including the largest number of studies was used. The criteria used to select the best estimate from individual studies included the following: 1) incidence study or incident case-control study; and 2) use of valid exposure assessment method, when available. If an estimate was available for workplace exposure separately from home exposure, this was preferred. The results are presented in table 4. PAF indicates the proportion of cases that is attributable to workplace exposure to ETS, i.e. the fraction of disease cases in a population that would not be observed if exposure was absent. Thus, it gives the potential of disease reduction by successful smoke-free workplace legislation that eliminates the hazard. The variation in PAFs for each country in table 4 reflects different estimates of exposure prevalence.

The proportion of lung cancer cases attributable to workplace ETS exposure varied from $1 \%$ in Finland and Sweden to $8 \%$ in Spain and the USA. PAF estimates for CHD ranged 1-9\%, asthma $1-29 \%$, COPD 1-14\%, LBW 1-16\%, stroke 1-24\% and severe pneumonia $2-32 \%$. The results suggested that the public health impact is substantial with the current exposure prevalences.

\section{SUMMARY AND CONCLUSIONS: POTENTIAL FOR PREVENTION}

According to recent estimates from Europe and the USA, significant numbers of workers are exposed to ETS in their workplaces. There is abundant evidence that workplace ETS exposure is causally linked to lung cancer and CHD, and there is strong evidence that such exposure is related to increased risk of asthma in adults. Strong evidence links reduced birthweight in newborns to ETS exposure of their mothers during pregnancy. Relatively strong evidence links ETS exposure to COPD and stroke. Rough estimates of PAFs due to workplace ETS exposure in Europe and the USA suggested that, at current exposure prevalences, the public health impact is substantial. The growing evidence highlights a need to protect workers against ETS exposure in their workplaces.

Experience from different parts of the world with national, statewide or local smoke-free workplace legislation has shown that such legislation is feasible to implement and leads to significant decline in ETS exposure of employees in the short term $[11,15,17,82]$ and long term $[12,14]$ compared with situations where there is no or are some voluntary smoking restrictions. These reductions in ETS exposure have been accompanied by health benefits, including reduced respiratory symptoms and acute myocardial infarctions and increased lung function levels [15-17]. Experience from Finland [12] shows that after implementation of national smoke-free workplace legislation, the attitudes of smokers change towards smoking restrictions in workplaces becoming favoured. A body of evidence also shows that such legislation leads to reduced active smoking, which adds to the potential public health benefit $[12,81]$. A recent meta-analysis based on 26 studies estimated that smoke-free workplaces would reduce the prevalence of smoking by $3.8 \%$ (95\% CI $2.8-4.7 \%)$, and that continuing smokers would consume on average 3.1 (95\% CI 2.4-3.8) fewer cigarettes [81]. It assessed that such legislation would reduce tobacco consumption per capita by $4.5 \%$ in the USA and $7.6 \%$ in the UK. The current situation of workplace smoking regulations around the world was reviewed recently by IARC [8] and can be checked on the web pages of the World Health Organization (www.who.int) and some national bodies, such as the Centers for Disease Control and Prevention (www.cdc.gov) in the USA.

Previous experience suggests that successful implementation of smoke-free workplace legislation should be preceded by an

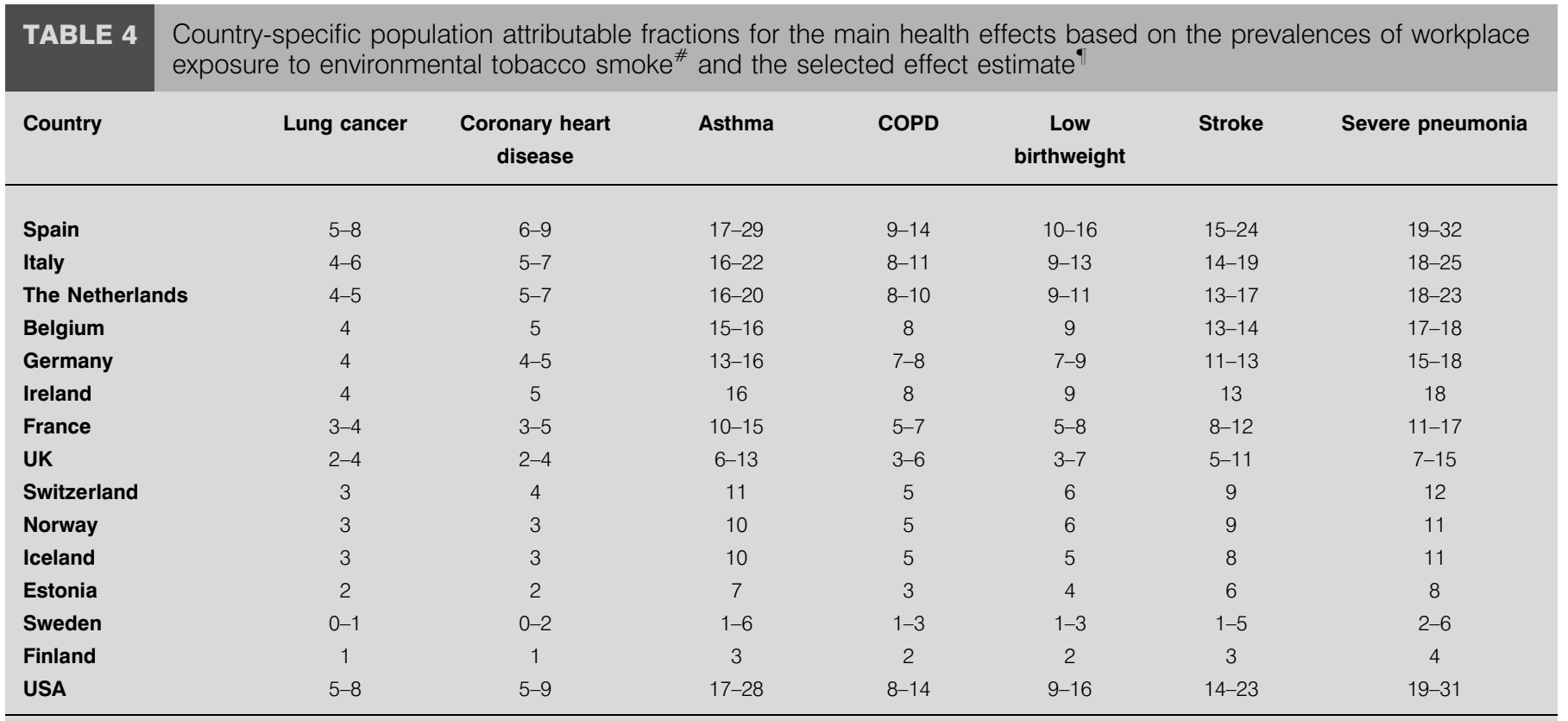

COPD: chronic obstructive pulmonary disease. ${ }^{\#}$ : provided in table 2 ; ${ }^{\bullet}$ : provided in table 3 . 
effective tobacco education campaign to increase the awareness of the public, employers, restaurant and bar owners, etc., of the health hazards related to passive smoking, to inform them about the new legislation and about how and where to get information and support for tobacco control methods. Preferably all forms of media should be used, as well as healthcare and other routes, in order to spread this information and awareness. During the implementation phase, occupational healthcare and primary healthcare in general should assist smoking cessation among employees, e.g. by organising or facilitating smoking-cessation programmes. The follow-up study from Finland [12] suggests that it is important to keep health promotion and smoking cessation programmes active in the long term after legislation to maintain and improve the reduction in workers' ETS exposure. The Californian follow-up study [14] emphasised the importance of enforcement efforts, such as continuous surveillance of compliance with the law, distribution of information about how to complain about any violations and rapid investigation of such complaints.

The experiences reported in the literature suggest that national smoke-free workplace legislation is a valuable tool to protect people against the adverse health effects of environmental tobacco smoke exposure.

\section{REFERENCES}

1 Jaakkola MS, Jaakkola JJK. Assessment of exposure to environmental tobacco smoke. Eur Respir J 1997; 10: 2384-2397.

2 Jaakkola MS, Samet JM. Occupational exposure to environmental tobacco smoke and health risk assessment. Environ Health Perspect 1999; 107: Suppl. 6, 829-835.

3 U.S. Environmental Protection Agency. Respiratory health effects of passive smoking: lung cancer and other disorders. EPA/600/6-90/006F. Washington DC, U.S. Environmental Protection Agency, Office of Health and Environmental Assessment, Office of Research and Development, 1992.

4 Jaakkola MS. Environmental tobacco smoke and respiratory diseases. In: Annesi-Maesano I, Gulsvik A, Viegi G, eds. Respiratory Epidemiology in Europe. Eur Respir Mon 2000; 5: No. 15, 322-383.

5 Jaakkola MS. Environmental tobacco smoke and health in the elderly. Eur Respir J 2002; 19: 172-181.

6 Jaakkola JJK, Jaakkola MS. Effects of environmental tobacco smoke on the respiratory health of children. Scand J Work Environ Health 2002; 28: Suppl. 2, 71-83.

7 Jaakkola MS, Jaakkola JJK. Effects of environmental tobacco smoke on the respiratory health of adults. Scand J Work Environ Health 2002; 28: Suppl. 2, 52-70.

8 IARC Monographs on the evaluation of carcinogenic risks to humans. Tobacco smoke and involuntary smoking. Vol. 83. Lyon, IARC, 2004; pp. 1189-1413.

9 Miettinen OS. Proportion of disease caused or prevented by a given exposure, trait or intervention. Am J Epidemiol 1974; 99: 325-332.

10 Greenland S. Applications of stratified analysis methods. In: Rothman KJ, Greenland S, eds. Modern Epidemiology. 2nd Edn. Philadelphia, Lippincott-Raven, 1998; pp. 281300.
11 Heloma A, Jaakkola MS, Kähkönen E, Reijula K. The shortterm impact of national smoke-free workplace legislation on passive smoking and tobacco use. Am J Public Health 2001; 91: 1416-1418.

12 Heloma A, Jaakkola MS. Four-year follow-up of smoke exposure, attitudes and smoking behaviour following enactment of Finland's national smoke-free workplace law. Addiction 2003; 98: 1111-1117.

13 Rothberg M, Heloma A, Svinhufvud J, Kähkönen E, Reijula K. Measurement and analysis of nicotine and VOCs in indoor air as an indicator of passive smoking. Ann Occup Hyg 1998; 42: 129-134.

14 Weber MD, Bagwell DAS, Fielding JE, Glantz SA. Longterm compliance with California's smoke-free workplace law among bars and restaurants in Los Angeles County. Tob Control 2003; 12: 269-273.

15 Eisner MD, Smith AK, Blanc PD. Bartenders' respiratory health after establishment of smoke-free bars and taverns. JAMA 1998; 280: 1909-1914.

16 Sargent RP, Shepard RM, Glantz SA. Reduced incidence of admissions for myocardial infarction associated with public smoking ban: before and after study. BMJ 2004; 328: 997-980.

17 Allwright S, Paul G, Greiner B, et al. Legislation for smokefree workplaces and health of bar workers in Ireland: before and after study. BMJ 2005; 331: 1117-1120.

18 Kauppinen T, Toikkanen J, Pedersen D, et al. Occupational exposure to carcinogens in the European Union. Occup Environ Med 2000; 57: 10-18.

19 Janson C, Chinn S, Jarvis D, Zock J-P, , Toren K, Burney P. Effect of passive smoking on respiratory symptoms, bronchial responsiveness, lung function, and total serum $\operatorname{IgE}$ in the European Community Respiratory Health Survey: a cross-sectional study. Lancet 2001; 358: 2103-2109.

20 Jousilahti P, Helakorpi S. Prevalence of exposure to environmental tobacco smoke at work and at home: 15year trends in Finland. Scand J Work Environ Health 2002; 28: Suppl. 2, 16-20.

21 Borland R, Pierce JP, Burns DM, Gilpin E, Johnson M, Bal D. Protection from environmental tobacco smoke in California. The case for a smoke-free workplace. JAMA 1992; 268: 749-752.

22 Thompson B, Emmons K, Abrams D, Ockene JK, Feng Z. ETS exposure in the workplace. Perceptions and reactions by employees in 114 work sites. Working Well Research Group (corrected). J Occup Environ Med 1995; 37: 1086-1092.

23 Ong MK, Glantz SA. Cardiovascular health and economic effects of smoke-free workplaces. Am J Med 2004; 117: 32-38.

24 Subramaniam RP, Turim J, Golden SL, Kral P, Anderson EL. An exploratory study of variation in exposure to environmental tobacco smoke in the United States. Risk Analysis 2001; 21: 561-574.

25 Bates MN, Fawcett J, Dickson S, Berezowski T, Garrett N. Exposure of hospitality workers to environmental tobacco smoke. Tob Control 2002; 11: 125-129.

26 Cenko C, Pisaniello D, Esterman A. A study of environmental tobacco smoke in South Australian pubs, clubs and cafes. Int J Environ Health Res 2004; 14: 3-11. 
27 Nebot M, López MJ, Gorini G, et al. Environmental tobacco smoke exposure in public places of European cities. Tob Control 2005; 14: 60-63.

28 Boffetta P. Involuntary smoking and lung cancer. Scand J Work Environ Health 2002; 28: Suppl. 2, 30-40.

29 Steenland K. Risk assessment for heart disease and workplace ETS exposure among nonsmokers. Environ Health Perspect 1999; 107: Suppl. 6, 859-863.

30 Jaakkola MS, Piipari R, Jaakkola N, Jaakkola JJK. Environmental tobacco smoke and adult-onset asthma: a population-based incident case-control study. Am J Public Health 2003; 93: 2055-2060.

31 Eisner MD, Balmes J, Katz PP, Trupin L, Yelin EH, Blanc PD. Lifetime environmental tobacco smoke exposure and the risk of chronic obstructive pulmonary disease. Environ Health 2005; 4: 7-14.

32 Jaakkola JJK, Jaakkola N, Zahlsen K. Fetal growth and length of gestation in relation to prenatal exposure to environmental tobacco smoke assessed by hair nicotine concentration. Environ Health Perspect 2001; 109: 557-561.

33 Bonita R, Duncan J, Truelsen T, Jackson RT, Beaglehole R. Passive as well as active smoking increases the risk of acute stroke. Tob Control 1999; 8: 156-160.

34 Nuorti JP, Butler JC, Farley MM, et al. Cigarette smoking and invasive pneumococcal disease. N Engl J Med 2000; 342: 681-689.

35 Reynolds P, Von Behren J, Fontham ETH, Wu A, Buffler P, Greenberg R. Occupational exposure to environmental tobacco smoke. JAMA 1996; 275: 441-442.

36 Boffetta P, Agudo A, Ahrens W, et al. Multicenter casecontrol study of exposure to environmental tobacco smoke and lung cancer in Europe. J Natl Cancer Inst 1998; 90: 1440-1450.

37 Kreuzer M, Krauss M, Kreienbrock L, Jockel K-H, Wichmann HE. Environmental tobacco smoke and lung cancer: a case-control study in Germany. Am J Epidemiol 2000; 151: 241-250.

38 Rapiti E, Jindal SK, Gupta D, Boffetta P. Passive smoking and lung cancer in Chandigarh, India. Lung Cancer 1999; 10: 607-610.

39 Zhong L, Goldberg MS, Gao Y-T, Jin F. A case-control study of lung cancer and environmental tobacco smoke among non-smoking women living in Shanghai, China. Cancer Causes Control 1999; 10: 607-616.

40 Wells AJ. Lung cancer from passive smoking at work. Am J Public Health 1998; 88: 1025-1029.

41 Zhong L, Goldberg MS, Parent M-E, Hanley JA. Exposure to environmental tobacco smoke and the risk of lung cancer: a meta-analysis. Lung Cancer 2000; 27: 3-18.

42 Wells AJ. Heart disease from passive smoking in the workplace. J Am Coll Cardiol 1998; 31: 1-9.

43 Kawachi I, Colditz GA. Workplace exposure to passive smoking and risk of cardiovascular disease: summary of epidemiologic studies. Environ Health Perspect 1999; 107: Suppl. 6, 847-851.

44 Thun M, Henley J, Apicella L. Epidemiologic studies of fatal and nonfatal cardiovascular disease and ETS exposure from spousal smoking. Environ Health Perspect 1999; 107: Suppl. 6, 841-846.

45 He J, Vupputuri S, Allen K, Prerost MR, Hughes J, Whelton PK. Passive smoking and the risk of coronary heart disease: a meta-analysis of epidemiologic studies. $N$ Engl J Med 1999; 340: 920-926.

46 Jousilahti P, Patja K, Salomaa V. Environmental tobacco smoke and the risk of cardiovascular disease. Scand J Work Environ Health 2002; 28: Suppl. 2, 41-51.

47 Kaur S, Cohen A, Dolor R, Coffman CJ, Bastian LA. The impact of environmental tobacco smoke on women's risk of dying from heart disease: a meta-analysis. J Womens Health (Larchmt) 2004; 13: 888-897.

48 Whincup PH, Gilg JA, Emberson JR, et al. Passive smoking and risk of coronary heart disease and stroke: prospective study with cotinine measurement. BMJ 2004; 329: 200-205.

49 Davis JW, Shelton L, Watanabe IS, Arnold J. Passive smoking affects endothelium and platelets. Arch Intern Med 1989; 149: 386-389.

50 Howard G, Burke GL, Szklo M, et al. Active and passive smoking are associated with increased carotid wall thickness: the Atherosclerosis Risk in Communities Study. Arch Intern Med 1994; 154: 1277-1282.

51 Leone A, Mori T, Bertanelli F, Fabiano P, Filippelli M. Indoor passive smoking: its effect on cardiac performance. Int J Cardiol 1991; 33: 247-251.

52 Greer JR, Abbey DE, Burchette RJ. Asthma related to occupational and ambient air pollutants in nonsmokers. $J$ Occup Med 1993; 35: 909-915.

53 Flodin U, Jönsson P, Ziepgler J, Axelson O. An epidemiologic study of bronchial asthma and smoking. Epidemiology 1995; 6: 503-505.

54 Thorn J, Brisman J, Torén K. Adult-onset asthma is associated with self-reported mold or environmental tobacco smoke exposures in the home. Allergy 2001; 56: 282-292.

55 Radon K, Busching K, Heinrich J, et al. Passive smoking exposure: a risk factor for chronic bronchitis and asthma in adults? Chest 2002; 122: 1086-1090.

$56 \mathrm{Ng}$ TP, Hui KP, Tan WC. Respiratory symptoms and lung function effects of domestic exposure to tobacco smoke and cooking by gas in non-smoking women in Singapore. J Epidemiol Community Health 1993; 47: 454-459.

57 Leuenberger P, Schwartz J, Ackermann-Liebrich U, et al. Passive smoking exposure in adults and chronic respiratory symptoms (SAPALDIA Study). Am J Respir Crit Care Med 1994; 150: 1222-1228.

$58 \mathrm{Hu}$ FB, Persky V, Flay BR, Richardson J. An epidemiological study of asthma prevalence and related factors among young adults. J Asthma 1997; 34: 67-76.

59 Larsson ML, Loit HM, Meren M, et al. Passive smoking and respiratory symptoms in the FinEsS Study. Eur Respir J 2003; 21: 672-676.

60 U.S. Department of Health and Human Services. The health consequences of smoking: chronic obstructive pulmonary disease. A report of the Surgeon General. DHHS Publication No. 84-50205. Washington DC, U.S. Department of Health and Human Services, Public Health Service, Office of the Assistant Secretary for Health, Office of Smoking and Health, 1984.

61 Robbins AS, Abbey DE, Lebowitz MD. Passive smoking and chronic respiratory symptoms in non-smoking adults. Int J Epidemiol 1993; 22: 809-817.

62 Vineis P, Airoldi L, Veglia F, et al. Environmental tobacco smoke and risk of respiratory cancer and chronic 
obstructive pulmonary disease in former smokers and never smokers in the EPIC prospective study. BMJ 2005; 330: 277-281.

63 McGhee SM, Ho SY, Schooling M, et al. Mortality associated with passive smoking in Hong Kong. BMJ 2005; 330: 287-288.

64 Jaakkola MS, Jaakkola JJK, Becklake MR, Ernst P. Effect of passive smoking on the development of respiratory symptoms in young adults: an 8-year longitudinal study. J Clin Epidemiol 1996; 49: 581-586.

65 Jayet P-Y, , Schindler C, Schwartz J, et al. Passive smoking exposure among adults and the dynamics of respiratory symptoms in a prospective multicenter cohort study. Scand J Work Environ Health 2005; 31: 465-473.

66 Carey IM, Cook DG, Strachan DP. The effect of environmental tobacco smoke on lung function in a longitudinal study of British adults. Epidemiology 1999; 10: 319-326.

67 Eisner MD. Environmental tobacco smoke exposure and pulmonary function among adults in NHANES III: impact on the general population and adults with current asthma. Environ Health Perspect 2002; 110: 765-770.

68 Masi MA, Hanley JA, Ernst P, Becklake MR. Environmental tobacco smoke and lung function in young adults. Am Rev Respir Dis 1988; 138: 296-299.

69 Misra DP, Nguyen RHN. Environmental tobacco smoke and low birth weight: a hazard in the workplace? Environ Health Perspect 1999; 107: Suppl. 6, 879-904.

70 Lindbohm M-L, Sallmén M, Taskinen H. Effects of exposure to environmental tobacco smoke on reproductive health. Scand J Work Environ Health 2002; 28: Suppl. 2, 84-96.

71 Peacock JL, Cook DG, Carey IM, et al. Maternal cotinine level during pregnancy and birth weight for gestational age. Int J Epidemiol 1998; 27: 647-656.

72 Windham GC, Eaton A, Hopkins B. Evidence for an association between environmental tobacco smoke exposure and birth weight: a meta-analysis and new data. Pediatr Perinat Epidemiol 1999; 13: 35-57.
73 Dejin-Karlsson E, Hanson BS, Ostergren PO, Sjoberg NO, Marsal K. Does passive smoking in early pregnancy increase the risk of small-for-gestational-age infants? Am J Public Health 1998; 88: 1523-1527.

74 Hanke W, Kalinka J, Florek E, Sobala W. Passive smoking and pregnancy outcome in central Poland. Hum Exp Toxicol 1999; 18: 265-271.

75 Windham GC, Hopkins B, Fenster L, Swan SH. Prenatal active or passive tobacco smoke exposure and the risk of preterm delivery or low birth weight. Epidemiology 2000; 11: 427-433.

76 Nafstad P, Fugelseth D, Qvigstad E, Zahlen K, Magnus P, Lindemann R. Nicotine concentration in the hair of nonsmoking mothers and size of offspring. Am J Public Health 1998; 88: 120-124.

77 Donnan GA, McNeil JJ, Adena MA, Doyle AE, O'Malley HM, Neill GC. Smoking as a risk factor for cerebral ischemia. Lancet 1989; 2: 643-647.

78 Iribarren C, Darbinian J, Klatsky AL, Friedman GD. Cohort study of exposure to environmental tobacco smoke and risk of first ischemic stroke and transient ischemic attack. Neuroepidemiology 2004; 23: 38-44.

79 Zhang X, Shu XO, Yang G, et al. Association of passive smoking by husbands with the prevalence of stroke among Chinese women nonsmokers. Am J Epidemiol 2005; 161: 213-218.

80 Nurminen MM, Jaakkola MS. Mortality from occupational exposure to environmental tobacco smoke in Finland. J Occup Environ Med 2001; 43: 687-693.

81 Fichtenberg CM, Glantz SA. Effect of smoke-free workplaces on smoking behaviour: systematic review. BMJ 2002; 325: 188-194.

82 Farrelly MC, Nonnemaker JM, Chou R, Hyland A, Peterson KK, Bauer UE. Changes in hospitality workers' exposure to second-hand smoke following the implementation of New York's smoke-free law. Tob Control 2005; 14: 236-241. 